\title{
POLÍTICAS PÚBLICAS NO ESPAÇO RURAL FLUMINENSE: ASPECTOS DO PAGAMENTO POR SERVIÇO AMBIENTAL E A IMPORTÂNCIA DA RECUPERAÇÃO DE ÁREAS DEGRADADAS EM BACIAS HIDROGRÁFICAS
}

\author{
PUBLIC POLICIES IN THE FLUMINESE RURAL SPACE: ASPECTS OF PAYMENT FOR ENVIRONMENTAL SERVICE AND THE \\ IMPORTANCE OF RECOVERY OF DEGRADED AREAS IN RIVER BASINS
}

\section{RESUMO}

Este texto trata a respeito das políticas públicas ambientais no espaço rural voltadas para conservação dos recursos hídricos. O objetivo principal do artigo é evidenciar os projetos voltados para recuperação de áreas degradadas em Bacias hidrográficas no Rio de Janeiro, especificamente nas Regiões hidrográficas I, II e III, que atendem pelo abastecimento de aproximadamente 12 milhões de pessoas residentes na Região Metropolitana. A nível de análise tomou-se como base o Programa Produtor de Águas e Florestas - PAF, desenvolvido pela Agência Nacional de Águas - ANA, para identificar potencialidades e limitações, bem como propor a incorporação de novas áreas ao programa no espaço rural fluminense. Neste sentido, a pesquisa cumpriu uma lógica contínua de investigação, cujos dados serão obtidos em trabalhos de gabinete, realizou-se uma ampla revisão bibliográfica e campo, para realização de entrevistas com os atores envolvidos no processo. Os resultados iniciais demonstraram que as políticas públicas voltadas para conservação e manutenção dos estoques hídrico é deficitária. Parte em função do arcabouço burocrático e jurídico nas instâncias municipais e parte devido a falta de políticas de Estado consolidadas para conservação da água.

Palavras-chave: Política pública. Espaço rural. Bacia hidrográfica. PSA.

\section{ABSTRACT}

This text deals with the environmental public policies in the rural space directed to the conservation of the water resources. The main objective of the article is to highlight the projects aimed at the recovery of degraded areas in Rio de Janeiro River Basins, specifically in the Hydrographic Regions I, II and III, which serve the supply of approximately 12 million people living in the Metropolitan Region. At the level of analysis was based on the Program Producer of Water and Forests - PAF, developed by the National Water Agency - ANA, to identify potentialities and limitations, as well as propose the incorporation of new properties to the program in the rural area of Rio de Janeiro. In this sense, the research realized a continuous logic of investigation, whose data will be obtained in cabinet work, was carried out a broad literature and field review, to conduct interviews with the actors involved in the process. The initial results showed that public policies aimed at conservation and maintenance of water stocks are deficient. Partly due to the bureaucratic and legal framework in the municipal instances and partly due to the lack of consolidated state policies aimed at conserving water.

Keywords: Public policy. Rural space. River basin. PSA.

\section{Paulo Roberto Palhares ${ }^{\text {a }}$}

a Universidade do Estado do Rio de Janeiro (UERJ), Rio de Janeiro, RJ, Brasil

DOI: 10.12957/geouerj.2020.48411

Correpondência: palhares.geo@gmail.com

Recebido em: 20 set. 2019

Revisado em: 25 out. 2019

Aceito em: $17 \mathrm{dez} .2019$ 


\section{INTRODUÇÃO}

O comprometimento dos recursos e o risco de escassez das fontes naturais alertam para uma situação de urgência, considerando o desenvolvimento de estudos e projetos destinados ao planejamento de ações que visem garantir a preservação e a disponibilidade hídrica para as gerações atual e futura.

Nesse contexto, e pelo alto grau de imprescindibilidade, a água deveria ser o bem natural mais preservado, com melhor acesso, inalienável e livre aos ecossistemas. No entanto, o que se observa é o comprometimento das fontes de forma generalizada, seja nos aspectos quantitativo e qualitativo, com nível de degradação elevado, sobretudo nas últimas décadas. Justifica-se tal afirmação considerando dados recentes sobre o crescimento das demandas produtivas, vinculadas a novas técnicas para reprodução ampliada do sistema econômico, associada as transformações nos hábitos de consumo na sociedade de maneira geral.

Ao mesmo tempo em que os seres humanos apresentam um relacionamento extremamente dependente, em se tratando do binômio homem-natureza, paradoxalmente estimulam ações degradantes que comprometem seu equilíbrio, sobretudo, em situações que envolvem o ciclo da água. A permanência de práticas predatórias em prol de benefícios políticos e econômicos vai de encontro a questões de ordem vital, contrariando as próprias expectativas humanas. Isto posto, entende-se que a busca por uma equivalência na relação homem-natureza é inadiável e crucial para garantir o bem-estar social, frente a crescente exploração dos recursos naturais.

$\mathrm{Na}$ historiografia, principalmente após a primeira Revolução Industrial, nota-se uma trajetória ascendente, um crescimento exponencial da produtividade, pautados na exploração da natureza. Os resultados ficam evidentes na paisagem que experimenta transformações em consequência da produção do espaço e do uso intensivo desses recursos, especificamente aqueles com alto grau de impacto, nocivos ao ambiente.

Neste sentido, cabe destacar que o aspecto mercantil da água pode ser evidenciado a partir dos processos territorializantes do espaço, especialmente pela propriedade privada da terra. Por conseguinte, espaços providos de fontes hídricas, e/ou entrecortados por canais fluviais passam a fazer parte da lógica imobiliária, especulativa, se tornando supervalorizados. Nesta perspectiva, Acselrad (2012), nos lembra que ao se apropriar de uma parcela do território, os sujeitos, ou instituições, assumem o controle dos recursos naturais nela existente, passando a influenciar na distribuição dos mesmos.

Destarte, outros fatores acometem a disponibilidade de água e podem comprometer o abastecimento prioritário. Dentre eles, se destaca a degradação das bacias hidrográficas, sobretudo em função das alterações no uso e cobertura da terra em áreas de nascentes e recargas fluviais. A impermeabilização do solo e a retirada 
de cobertura florestal afetam a dinâmica cíclica da água à medida que as fases de interceptação, infiltração, escoamento subterrâneo e acumulação passam a ser substituídos pelo fluxo superficial aumentando as perdas de água e comprometendo os estoques para os usos múltiplos da água.

Estima-se que o consumo diário per capta de água seja de 2 a 4 litros, inclusos as fórmulas compostas como refrigerantes, sucos, água, cerveja, espumantes etc. (CHRISTOFIDIS, 2001). Ainda neste mesmo intervalo de tempo, o consumo salta de 2.000 a 3.000 litros por pessoa quando são considerados os alimentos consumidos e a quantidade de água necessária para produzi-los (BARBOSA, 2014. p. 66). Esse é o principal motivo que eleva o setor agropecuário ao patamar de maior consumidor de água doce do Planeta, seguido pelos usos industrial e doméstico. Somente a agricultura responde por $70 \%$ de toda água consumida, e estão relacionadas principalmente a usos consuntivos, em que há perda volumétrica no reservatório ou córrego de origem, mantendo, por exemplo, os sistemas de irrigação (ibid.).

Apesar da constatação de que no Brasil a disponibilidade hídrica é satisfatória, considerando-se a demanda per capita, tem-se que sua distribuição espacial ocorre de forma desigual pelo território. O caso da Região hidrográfica amazônica é emblemático. Concentra cerca de $80 \%$ da água doce (Drinkwater) do país, ao passo que detém apenas $5 \%$ da população total do país (IBGE, 2017). No caso da Região Sudeste a situação é oposta. Embora represente apenas $10 \%$ do território nacional, abarca a maior densidade demográfica, e, segundo Nascimento $(2017$, p. 110) "guarda somente $6 \%$ da água doce disponível no país, ficando em penúltimo lugar comparado com outras regiões do Brasil no tocante a disponibilidade hídrica por habitante ( $\mathrm{m}^{3} /$ hab./ano) ".

Acrescenta-se a isso os problemas relacionados ao índice de qualidade da água em áreas urbanas. Como exemplo cita-se o aporte de sedimentos e resíduos nos corpos hídricos que entrecruzam localidades densamente povoadas, como as Regiões Metropolitanas e grandes cidades do interior. Em diversos casos a falta de políticas públicas em serviços de saneamento básico, acabam por comprometer o uso, evidenciando, portanto, o alto risco para o abastecimento público, em especial dessas regiões onde são registradas as maiores demandas.

Entre os anos de 2013 e 2014 as maiores Regiões Metropolitanas do Brasil, São Paulo e Rio de Janeiro respectivamente, tiveram de conviver com a ameaça da falta d'água para os usos prioritários. Neste período, em função de um conjunto de fatores climáticos, a Região passou por estiagens prolongadas onde o baixo nível dos reservatórios demandou uma série de intervenções na gestão hídrica, inclusive a implantação de rodízios no abastecimento público de água (NASCIMENTO, 2017).

Diante do exposto, pretende-se com essa pesquisa analisar e discutir formas que possam viabilizar a ampliação e manutenção dos estoques de água para Região Metropolitana do Rio de Janeiro - RMRJ. Para isso 
será necessário ir a fundo nas políticas públicas indutoras da preservação e do ordenamento territorial ambiental, sobretudo, no espaço rural fluminense. Esses setores concentram as principais áreas de recarga hídrica e lençóis freáticos das principais Bacias hidrográficas do Estado, que juntamente com sistemas de transposição, garantem o abastecimento público de água.

A proposta de recuperação de áreas degradadas nas bacias hidrográficas pode causar impactos positivos no enfrentamento de crises hídricas e garantia do abastecimento para gerações futuras. A dificuldade em obter sistemas de "produção" e reaproveitamento de água nas grandes cidades eleva o grau de importância das áreas rurais do Estado, dado seu potencial para implantação de políticas públicas de preservação ambiental. Cita-se, por exemplo, a implementação do Pagamento por Serviço Ambiental - PSA, principalmente através do Programa Produtor de Águas e Florestas - PAF, como alternativa para recuperação de ambientes naturais capazes de contribuir com o aumento dos estoques hídricos e a redução de problemas no abastecimento de água na RMRJ.

Considerando as questões apresentadas e a divisão das Regiões hidrográficas - Rh's do Rio de Janeiro, optou-se por um recorte espacial que inclui o contexto rural das Rh's I, II e III, dada a importância para o abastecimento de milhares de residentes na RMRJ e Baixada Fluminense (CEDAE, 2016). Além disso, a região envolve o município de Rio Claro, um dos pioneiros na implantação dos Programas no Estado e que servirá como parâmetro para investigação das hipóteses aqui apresentadas.

Neste sentido, pretende-se responder algumas questões relacionadas a eficácia dos programas e a possibilidade de abrangência para outras localidades do Estado. Sendo assim, é crucial identificar e examinar as políticas públicas ambientais em variadas escalas de implementação nas áreas supracitadas, pelos menos nos últimos 20 anos. Ademais, será necessário verificar a composição do arcabouço legal considerando as instâncias Federal, Estadual e Municipal, incidentes sobre os aspectos ambientais, sobretudo, da gestão dos recursos hídricos.

Buscar-se-á também compreender e discutir a apropriação dos espaços nas bacias hidrográficas e suas materializações nas propriedades rurais, com base nas políticas de desenvolvimento territorial. Dessa forma será possível analisar os tipos de degradação ambiental que atingem diretamente as áreas de recarga e as nascentes dos rios, identificando os principais impactos negativos ao ambiente. Por fim, serão avaliados o papel do Estado na condução dos processos de implantação dos programas, analisando suas fragilidades e contradições com apontamento de áreas alternativas e possíveis produtores rurais interessados em aderir aos projetos de recuperação ambiental.

Área de estudo 
Através da Lei Complementar Federal $n^{\circ} 20$, de $1^{\circ}$ de julho de 1974, que dentre outras ações, fundiu os Estados da Guanabara e do Rio de Janeiro, foi criada a Região Metropolitana do Estado do Rio de Janeiro RMRJ. A realização deste recorte espacial atendeu os anseios e necessidades do controle políticoadministrativo de áreas cujos domínios e afinidades as distinguem das demais áreas do Estado. O número de municípios pertencentes a esta região foi sendo alterado ao longo do tempo, e hoje abarca 21 unidades municipais, concentrando uma população com cerca de 12 milhões de pessoas, $73,7 \%$ da população total do Estado (CEPERJ, 2013).

A delimitação das Regiões hidrográficas - Rh's do Rio de Janeiro sucedeu a criação do Conselho Estadual de Recursos Hídricos - CERHI pela Lei no 3.239/19990, formando um órgão colegiado, responsável pela promoção e implementação de diretrizes da Política Estadual de Recursos Hídricos - PERH. As Rh's foram definidas pela resolução № 107 de 22 de maio de 2013, onde o Conselho definiu nove Regiões Hidrográficas para o Estado (Figura 1), contribuindo efetivamente com a governança das águas Estaduais no tocante à gestão dos Comitês de bacia.

Figura 1. Divisão estratégica das Regiões hidrográficas do Rio de Janeiro. Fonte: Elaborado pelos autores.

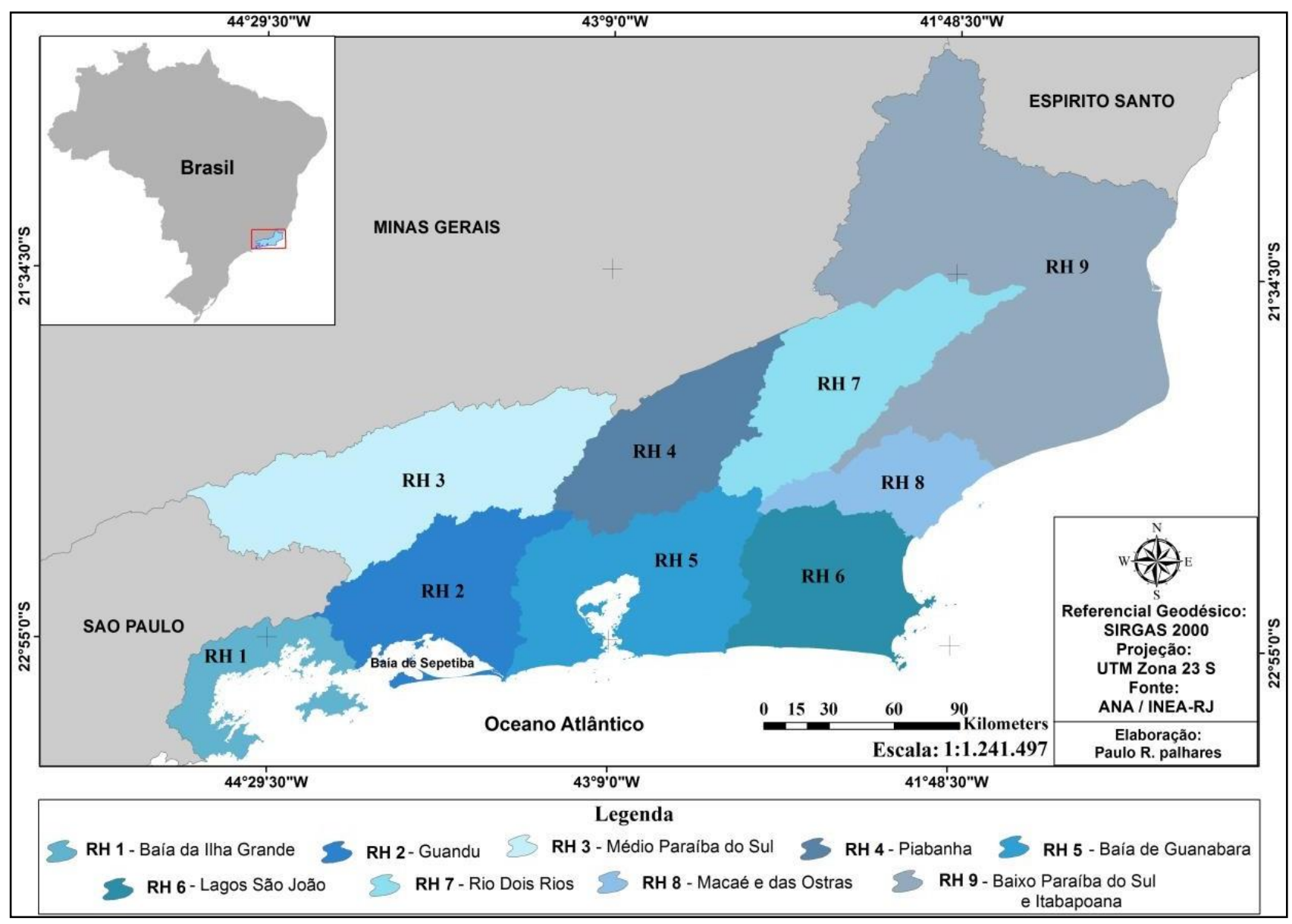


As Regiões hidrográficas I, II e III, área focal das pesquisas, adquirem importância estratégica para o Rio de Janeiro. Especialmente a Rh II, intitulada Bacia do Guandu, por englobar uma das principais bacias hidrográficas do Estado, e todo o Sistema Guandu, que responde pelo abastecimento de pouco mais de 9,6 milhões de habitantes, 78\% deles, residentes na RMRJ (CEDAE, 2016; IBGE, 2017). Essa bacia forma uma complexa estrutura responsável por abastecer doze Municípios no Estado, sendo eles Itaguaí, Seropédica, Paracambi, Japeri, Queimados, Nova Iguaçu, Rio de Janeiro, Mesquita, Nilópolis, São João de Meriti, Belford Roxo e Duque de Caxias (CEDAE, 2017).

A medida que as demandas por água vão sendo ampliadas nas áreas urbanas e os produtores rurais adquirindo novos territórios, entende-se que há uma extrema necessidade em desenvolver ações preservacionistas. Por conseguinte, esse foi o motivo determinante para eleição desta área como objeto de estudo do presente projeto, considerando as características naturais e sua importância estratégica (Figura 2).

Figura 2. Divisão estratégica das Regiões hidrográficas do Rio de Janeiro. Fonte: Elaborado pelos autores.

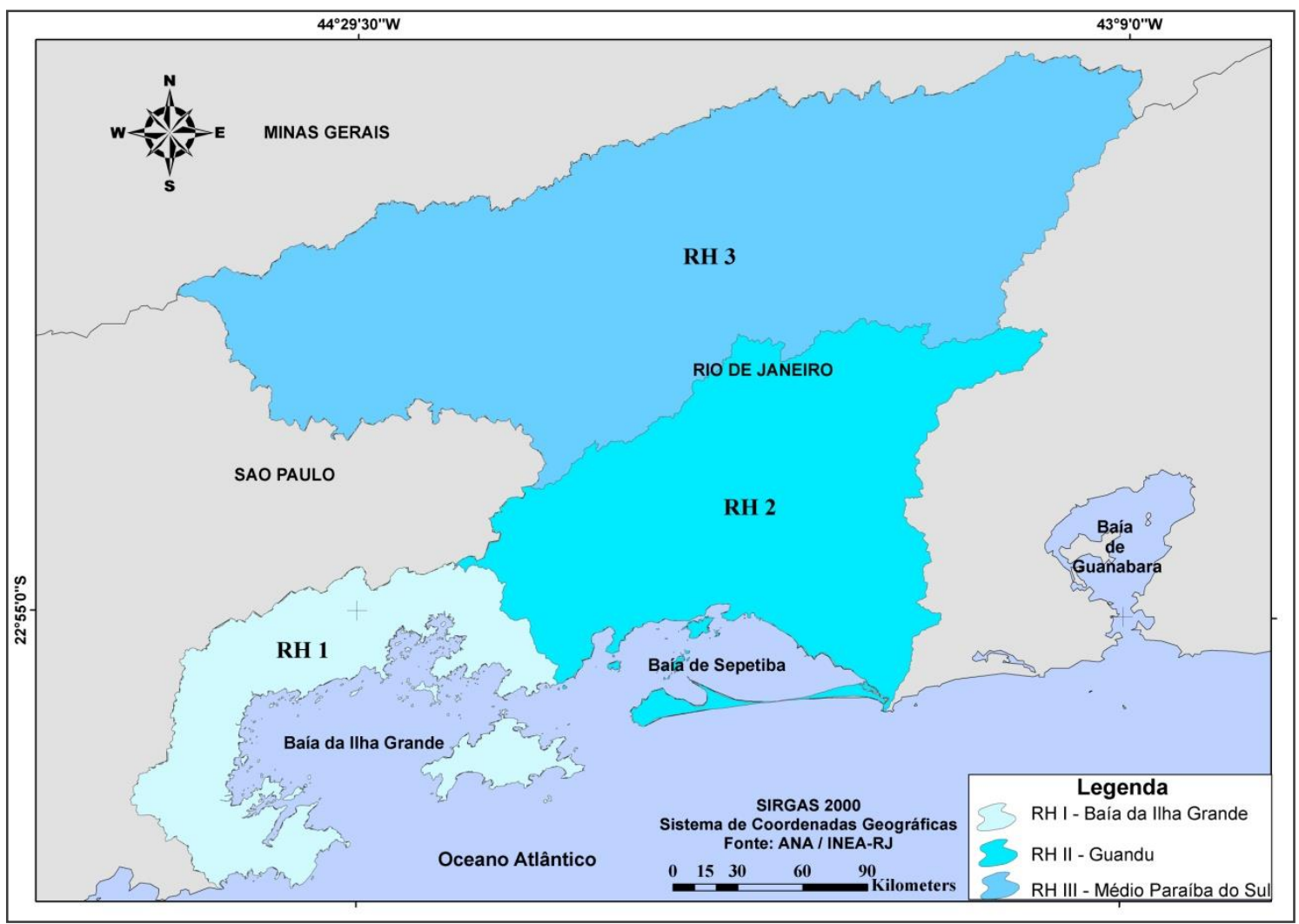

Os potenciais locacional e econômico, associados a disponibilidade hídrica na região atraem investimentos diretos tanto na área industrial quanto no incremento das estruturas agrícolas, merecendo 
assim, maiores atenções quanto a manutenção das estruturas e políticas ambientais. Estudos prognósticos realizados nos últimos anos revelaram que as demandas não são compatíveis com a capacidade de suporte, o que justifica a necessidade e o fortalecimento de políticas públicas e programas de cunho preservacionista nesta região. $O$ desafio investigativo que se coloca permitirá o entendimento dos resultados reais dos investimentos feitos pelo poder público e proprietários rurais na manutenção da natureza no contexto da dinâmica do sistema capitalista em vigência.

\section{Aspectos conceituais e metodológicos}

A ação do Estado e sua regulação estatal na viabilização de projetos visando o ordenamento territorial e ambiental é fundamental. Segundo Moraes (apud ACSELRAD, 2010), é através da legislação que ele cria limitações, impedindo ou induzindo os usos do solo. Por meio do planejamento o Estado busca orientar as tendências presentes, direcionando-as para padrões não degradantes de usos ou estimulando a sua devastação. Através do sistema de gestão as agências públicas buscam mediar ou intervir nos usos existentes, apoiando o estabelecimento de consensos possíveis ou intercedendo por uma das partes interessadas.

A adoção do conceito e da Bacia hidrográfica como unidade de gestão territorial, assim como dos recursos hídricos, extrapolará os tradicionais limites político-administrativos exercidos pelas fronteiras Municipais. Embora haja divergências quanto a admissão deste recorte espacial sobrepondo divisões políticoterritoriais, corrobora-se com os autores Tundisi (2003), Carvalho-Penna (2006), Machado (2013) e Nascimento (2011) pois atestam a adoção desta parcela singular para o planejamento e desenvolvimento, assim como para controle e gestão dos recursos hídricos. Embora configure um sistema complexo, dado o número de elementos, variáveis e a relação mútua entre eles, possibilita a análise integrada do ambiente, auxiliando numa avaliação objetiva dos aspectos físicos, econômicos e sociais (ibid.).

Como Pagamento por Serviço Ambiental - PSA, considera-se a metodologia desenvolvida para o pagamento de compensação financeira ao produtor que opte por adotar práticas em prol de melhorias ambientais especificadas. Mais do que a compensação financeira, segundo Castello Branco (2015), para que um projeto possa ser classificado como PSA deve respeitar condições como: ser uma transação voluntária; ter um uso ambiental bem definido (ou um tipo de uso da terra que assegure este serviço); ser "comprado" por ao menos um provedor de serviços; ter pelo menos um provedor de serviços e o provedor (ofertante) deve assegurar a provisão do serviço prestado (condicionalidade).

O Programa Produtores de Água e Florestas - PAF tem princípios estabelecidos pela Agência Nacional de Águas - ANA, e são estabelecidos com base no "provedor recebedor", referente a proprietários rurais, e no "beneficiário pagador", incluindo órgãos federais, estaduais, municipais e Comitê de bacias. O Programa 
visa induzir ações de manejo corretas em áreas produtivas e de conservação, atuando de forma conjunta, com apoio técnico e operacional oferecido pelas instituições envolvidas.

Como áreas degradas entende-se que são localidades nas bacias cuja cobertura original sofreu alterações, e serão identificadas com base nos planos de recuperação propostos no PAF (CASTELLO BRANCO, 2015; NASCIMENTO 2017). Serão consideradas as condições das áreas de recarga hídrica, conservação de vegetação natural, plantios de vegetação arbórea, culturas perenes, proteção de nascentes, cercando e cuidando da vegetação, proteção de margens de cursos d'água, na conservação de solos mediante construção de terraços em curva de nível, construção de barragens ou caixas de acúmulo e infiltração de água, plantio direto para culturas anuais, reforma e bom manejo de pastagens e descompactação de solos (ITPA, 2018).

A pesquisa tem como base exploratória o levantamento bibliográfico através de buscadores disponibilizados nas bibliotecas, especialmente, nas Universidades públicas, pré-determinadas para este fim. Dentre as instituições e sistemas consultados cita-se: Universidade Federal Fluminense (Sistema Pergamum), Universidade Federal do Rio de Janeiro (Sistema Minerva), Universidade Federal Rural do Rio de Janeiro (Sistema Pergamum), Centro de Documentação Ivan de Otero Ribeiro - CPDA/UFRRJ além das buscas realizadas na base de periódicos da CAPES

A pesquisa cumpre uma lógica contínua de investigação, cujos dados serão obtidos em trabalhos de gabinete e campo. Como forma de organização optar-se-á pela divisão do cronograma de execução em três etapas, indissociáveis, diga-se de passagem, sendo necessário o entrecruzamento das mesmas de modo a sustentar os argumentos apresentados e a operacionalidade da proposta. Em linhas gerais, a pesquisa se dá em uma sequência sistemática, composta por três fases fundamentais, conforme proposição de Souza et al. (2003), elencadas a seguir:

1. Analítica: nesta fase, são selecionados os dados e informações necessários a elaboração dos mapas de localização considerando a RMRJ e as Regiões Hidrográficas I, II e III. Seguiu-se com a delimitação das bacias, com destaque à elaboração dos mapas temáticos, referentes ao uso e cobertura da terra, usos da água e propriedades rurais.

2. Agregação e síntese: pautada na seleção dos critérios já elaborados na fase anterior, segue-se com a identificação e caracterização dos principais problemas ambientais e as políticas públicas ambientais na área de estudo. Serão analisados a configuração dos arranjos espaciais e dinâmicas territoriais para compreender ações de agentes organizadores desse espaço, tendo como referencial a os usos, funções e aquisição de água no espaço rural. 
3. Integração dialógica: integração dos parâmetros de forma sistêmica, mantendo necessariamente uma visão holística dos ambientes, já a par do mapeamento e das ações do poder público, bem como das propriedades rurais, citados anteriormente.

Dentre as estratégias metodológicas adotadas, se destaca a leitura e análise atenta das Atas de Reuniões anteriores dos Comitês de Bacia (ordinária, extraordinária e câmaras técnicas) e suas publicações como boletins, comunicados e projetos de pesquisa.

Considerando que informações necessárias ao cumprimento dos objetivos da pesquisa poderiam não ter sido registradas nos documentos citados anteriormente, optou-se pela realização de "entrevistas com pessoas-chave", conforme Tavares et al. (1996), para obter um diagnóstico das condições do território em lugares específicos da região. Os entrevistados serão escolhidos levando em conta suas representações frente à comunidade local, gestores públicos, técnicos, Professores da Universidade Federal Rural do Rio de Janeiro - UFRRJ, ambientalistas e membros dos Comitês de bacia e produtores rurais.

Os dados cartográficos utilizados para confecção dos mapas são extraídos, basicamente, do Sistema disponibilizado pela Agência de Bacia do Vale do Paraíba - AGEVAP, juntamente com os respectivos Comitês de bacia, por exemplo o SIGA GUANDU, que mantém uma base cartográfica contínua do Brasil e do Rio de Janeiro. Nestes ambientes virtuais se encontram disponíveis dados oficiais elaborados por órgãos federais e estaduais como Instituto Brasileiro de Geografia e Estatística - IBGE, Agência Nacional de Águas - ANA, Serviço Geológico do Brasil - CPRM, Instituto Estadual do Ambiente - INEA, Departamento de recursos minerais - DRM e Instituto Nacional de Pesquisas Espaciais - INPE. Inicialmente foram extraídos arquivos no formato shape file (.shp) do Brasil (político), Estado do Rio de janeiro (político), delimitação da Região Hidrográfica 2 (físico) e imagem do satélite LANDSAT 8 cobrindo toda a Bacia. Os dados referentes aos municípios da RMRJ foram obtidos no site da Fundação Centro Estadual de Estatística, Pesquisa e Formação de Servidores Públicos Fundação CEPERJ, assim como dados estatísticos da população e atividades econômicas.

Por fim, são consideradas também informações importantes obtidas em conversas informais com funcionários da CEDAE e da LIGHT acerca do fornecimento de água e manutenção dos sistemas de abastecimento e fontes de captação. Ressalta-se que não houve preparação de questionário específico, porém, alguns questionamentos acabaram sendo recorrentes como por exemplo: quais são os principais problemas relacionados a água nesta localidade?; existem conflitos potenciais ou já desencadeados pelo uso da água?; qual a percepção sobre o abastecimento de água na RMRJ?; vislumbra alguma solução para o enfrentamento da crise hídrica?; como são tratadas as questões ligadas ao saneamento básico?; qual a percepção dos produtores rurais sobre os programas de Pagamento por Serviço Ambiental - PSA e o Produtor de Águas e Florestas - PAF? 


\section{CONSIDERAÇÕES FINAIS}

Embora a pesquisa esteja em curso algumas hipóteses levantadas previamente podem ser confirmadas. Ainda que incorporada nas políticas de desenvolvimento, as políticas ambientais referentes aos instrumentos de intervenção do Estado na garantia da conservação, proteção e gestão ambiental e melhoria da qualidade de vida das populações, têm ficado aquém do esperado, sendo suplantadas pela lógica desenvolvimentista inerentes ao sistema vigente.

O espaço rural do Rio de Janeiro apresenta características distintas da maioria dos Estados brasileiros. Ao longo das pesquisas serão aprofundadas questões relacionadas a dicotomia entre rural-urbano no Estado, mas por hora, é necessário evidenciar a existência de um espaço híbrido no meio rural Fluminense. Como destacado também por inúmeros autores, isso é resultado de um processo de Metropolização do espaço, que é refletido através das urbanidades observadas no campo.

Com relação a produção agrícola, pode-se dizer que o campo apresenta um espaço produtivo múltiplo, marcado pela forte presença de agricultura familiar e baixo número de grandes latifúndios monocultores. Para desvendar o espaço rural do Rio de Janeiro é necessário compreender sua estrutura, ou seja, os agentes sociais e os diferentes interesses no uso do solo, com atividades e relações produtivas distintas.

Diante deste cenário, a implantação de programas que visem a recuperação de áreas estratégicas para o abastecimento público de água torna-se um verdadeiro desafio às autoridades e organismos competentes. Parte dessa constatação inclui a percepção dos produtores rurais em relação a disponibilidade hídrica, que é divergente de pessoas residentes na Região Metropolitana. Logo, a implantação de projetos para manutenção de uma forma de utilização do solo que proporcione a permanência da água na Bacia hidrográfica por mais tempo é fundamental, considerando as demandas crescentes.

O programa Produtor de Águas e Florestas - PAF, cujo principal objetivo é promover desenvolvimento de iniciativas voltadas à conservação dos recursos hídricos com vistas a melhoria das condições em Bacias hidrográficas, precisa ser expandido. Inicialmente, identificou-se algumas barreiras impeditivas, como a falta de recursos financeiros, ausência de um arcabouço legal consolidado e suficiente para respaldar produtores e proprietários de terra, especialmente nas instâncias municipais. Cabe destacar o trabalho que vem sendo executado pelo Comitê de Bacia do Rio Guandu, tanto nas tentativas de ampliação do número de propriedades incluídas no PSA quanto nos investimentos em saneamento rural.

Embora algumas hipóteses lançadas inicialmente tenham sido comprovadas, a pesquisa encontra-se distante do fim, em função de novas proposições que estão sendo alcançadas com o desenrolar das atividades exploratórias. Alguns pontos ainda precisam ser trazidos à arena, sob a luz da ciência, para serem discutidos 
de modo a ampliar o número de adesões aos programas supracitados para contribuir efetivamente na redução dos riscos de uma nova crise hídrica.

Por conseguinte, uma das possíveis soluções passa, necessariamente, pela construção e/ou ativação de representações simbólicas das paisagens do campo. Além dos aspectos físicos, é preciso resgatar e pensar a perspectiva paisagística como representação da identidade do lugar para valorizar as experiências vividas. Neste ínterim, a proposta de desenvolvimento turístico nessas áreas pode contribuir de fato para ampliação dos programas de recuperação das áreas de recarga e nascentes degradadas pelo uso intensivo, sem que haja uma redução da produtividade agrícola.

\section{REFERÊNCIAS}

ANA - Agência Nacional das Águas (Brasil). Conjuntura dos recursos hídricos no Brasil 2013. Brasília, 2013.

ANA. Agência Nacional de Águas. Atlas esgotos: despoluição de bacias hidrográficas; panorama nacional. Agência Nacional de Águas. Secretaria Nacional de Saneamento Ambiental. Brasília. 2017.

ACSELRAD, Henri. (Org.). Conflitos Ambientais no Brasil. Rio de Janeiro: Relume Dumará. 2004.

ACSELRAD, Henri. Desigualdade ambiental e acumulação por espoliação: o que está em jogo na questão ambiental? e-cadernos, CES 17. 2012. 164-183. 2012.

ACSELRAD, Henri; BEZERRA, Gustavo das Neves. Desregulação, deslocalização e conflito ambiental: considerações sobre o controle das demandas sociais. In: ALMEIDA, Alfredo Wagner Berno de; et al (Orgs.). Capitalismo globalizado e recursos territoriais: fronteiras da acumulação no Brasil contemporâneo. Rio de Janeiro: Lamparina, 2010, p. 179-209.

BARBOSA, Vanessa. A última gota. 1a edição. São Paulo. Planeta. 2014.

Brasil. Lei no 9.433, de 8 de janeiro de 1997. Brasil, 1997. Disponível em: <http://www.planalto.gov.br/ccivil_03/Leis/L9433.htm>. Acesso em: 15 abr. 2014.

BRAGA, Benedito; TUNDISI, José Galizia; TUNDISI, Takako Matsumura; CIMINELLI, Virginia S. T (Orgs.). Águas doces no Brasil: capital ecológico, uso e conservação. 4ạ ed. São Paulo. Escrituras Editora. 2015.

CASTELLO BRANCO, Maurício Ruiz. Pagamento por serviços ambientais: da teoria à prática. ITPA, 2015. $188 \mathrm{p}$.

CARVALHO-PENNA, Beatriz de. Gestão de recursos hídricos: aspectos teórico-práticos da Bacia do Guandu. Rio de Janeiro, 2006. 387f. Tese (Doutorado). IGEO/Programa de Pós- graduação em Geologia, Universidade Federal do Rio de Janeiro, Rio de Janeiro, 2006.

CERHI - Conselho Estadual de Recursos Hídricos. № 107 de 22 de maio de 2013. Disponível em: http://www.ceivap.org.br/legirj/ResolucoesCERHI/Resolucao-CERHI\%20107.pdf Acesso em 17/03/2017.

CHRISTOFIDIS, Demetrios. Olhares sobre a Política de Recursos Hídricos no Brasil: o caso da bacia do rio São Francisco. Brasília/DF. 2001.

FERREIRA, Alvaro; RUA, João; MATTOS, Regina Célia. Metropolização do espaço, gestão territorial e relações urbano-rurais: algumas interações possíveis. Geo UERJ. Rio de Janeiro. Ano 16. № 25, v. 2. 2014. p. 477-504.

GRIGG, D. Dynamics of Agricultural Change: the Historical Experience. London: Hutchinson, 1982.

GRIGG, D. An Introduction of Agricultural Geography. London: Hutchinson, 1984.

IBGE. Características da população e dos domicílios: resultados do universo. Censo demográfico 2010. Rio de Janeiro. Site: https://cidades.ibge.gov.br. Acesso em: 17/03/2017.

IBGE. Censo Agropecuário 2017 - Resultados preliminares. Rio de Janeiro. Site: https://cidades.ibge.gov.br. Acesso em: 12/08/2018

ITPA - Instituto Terra de Preservação Ambiental. Produtores de Água e floresta. Disponível em: <http://www.itpa.org. br/?page_id=497>. Acesso em: 25 out. 2018. 
MACHADO, G. Por uma territorialização da Bacia Hidrográfica. In: Estudos Territoriais na Ciência Geográfica. Saquet, M. A. (org) Ed. Outras Expressões, 2013, p. $107-128$.

MARAFON, G. J. $O$ espaço rural em transformação: as novas relações campo $x$ cidade no estado do Rio de Janeiro. In: CONGRESO LATINOAMERICANO DE SOCIOLOGÍA RURAL, 8., 2010, Porto de Galinhas. Anais... Porto de Galinhas: ALASRU, 2010. p. 1-20.

Disponível em: <http://www.alasru.org/wp-content/uploads/2011/07/GT-1-Glaucio-Jose-Marafon. pdf>. Acesso em: 20 ago. 2014.

NASCIMENTO, Flávio Rodrigues do. Categorização de Usos Múltiplos dos Recursos Hídricos e Problemas Ambientais. Revista da ANPEGE, v. 7, 2011, p. 81-97.

PALHARES, Paulo Roberto. Categorização dos usos, usuários e funções da água no médio curso da Bacia hidrográfica do rio Guandu RJ. Niterói, 2018. 125 f. Dissertação (Mestrado em Geografia). Instituto de Geociências. Universidade federal Fluminense, Niterói, 2018.

SANTOS, Erika Vanessa Moreira; HESPANHOL, Rosangela Aparecida de Medeiros. As múltiplas leituras do espaço rural. ACTA Geográfica. Boa Vista. Ed. Esp. Geografia Agrária. 2013. P. 81-101.

SANTOS, Milton. A natureza do espaço: técnica e tempo, razão e emoção. São Paulo: Hucitec, 1996.

SOUZA, M. J. N. Questões Metodológicas da Geografia Física. Fortaleza. U EC. CCT - Departamento de Geociências. 2000.

TAVARES, E. D. et al. Uso do método de entrevistas com pessoas-chaves para o diagnóstico territorial rápido dos tabuleiros costeiros de Sergipe. Geotextos. v1. n. 2. Aracaju, p 1996. P. $30-44$.

TUNDISI, J. G. Água no século XXI: enfrentando a escassez. São Carlos. RIMA. 2003.

COELHO, Frederico Menezes; ANTUNES, Júlio Cesar Oliveira. Balanço hídrico da Bacia Hidrográfica do Rio Guandu com as novas demandas por água e com a expansão prevista. In: TUBS, Décio; ANTUNES, Julio Cesar Oliveira; VETTORAZZI, Janaina Silva (Orgs.). Bacia Hidrográfica dos Rios Guandu, da Guarda e Guandu Mirim: experiências para a gestão dos recursos hídricos. Comitê da Bacia Hidrográfica Guandu. Rio de Janeiro. Inea. 2012. 